\author{
В. С. Исаченков, С. Е. Арико, В. А. Симанович
}

Белорусский государственный технологический университет

\title{
К ВОПРОСУ ВЫБОРА ПАРАМЕТРОВ ТЕХНОЛОГИЧЕСКОГО ОБОРУДОВАНИЯ КОЛЕСНЫХ ТРЕЛЕВОЧНЫХ МАШИН
}

При лесосечных работах на участках со слабой несущей способностью почвогрунтов повышение тягово-динамических качеств колесных трелевочных машин может быть достигнуто совершенствованием конструкции двигателя, трансмиссии, ходовой части или технологического оборудования. Такими изменениями можно добиться перераспределения нагрузок на несущие системы в процессе движения и снизить динамическую нагруженность машин, увеличив их производительность и долговечность. Основным путем дальнейшего развития конструкции колесных трелевочных машин, на наш взгляд, является совершенствование технологического оборудования, правильный выбор параметров которого обусловлен природно-климатическими условиями лесозаготовок.

В статье представлены математические модели движения колесной трелевочной машины с различным по конструктивным особенностям прицепным технологическим оборудованием. В качестве опорной системы принималась трехосная тележка.

Проведена теоретическая оценка динамической нагруженности основных элементов конструкции колесной трелевочной машины и технологического оборудования.

На основе анализа полученных результатов предложен наиболее рациональный вариант параметров конструкции технологического оборудования для колесной трелевочной машины при работе на грунтах со слабой несущей способностью, который позволяет минимизировать динамическую нагруженность и энергетические затраты в процессе трелевки.

Ключевые слова: математическая модель, колесная трелевочная машина, технологическое оборудование.

Для цитирования: Исаченков В. С., Арико С. Е., В. А. Симанович В. А. К вопросу выбора параметров технологического оборудования колесных трелевочных машин // Труды БГТУ. Сер. 1, Лесное хоз-во, природопользование и перераб. возобновляемых ресурсов. 2021. № 2 (246). С. 218-223.

\section{S. Isachenkov, S. Ye. Ariko, V. A. Simanovich \\ Belarusian State Technological University \\ ON THE QUESTION OF CHOOSING THE PARAMETERS \\ OF THE TECHNOLOGICAL EQUIPMENT OF SKIDDERS}

When logging operations in areas with weak bearing capacity of soils, an increase in the traction and dynamic qualities of wheeled skidders can be achieved by improving the design of the engine, transmission, chassis or technological equipment. Such changes can achieve a redistribution of loads on the load-bearing systems in the process of movement and reduce the dynamic load of machines, increasing their productivity and durability. The main way to further develop the design of wheeled skidders, in our opinion, is to improve the technological equipment, the correct choice of parameters of which is due to the natural and climatic conditions of logging.

The article presents mathematical models of the movement of a wheeled skidder with trailed technological equipment of different design features. A three-axle bogie was taken as a support system.

A theoretical assessment of the dynamic loading of the main structural elements of a wheeled skidder and technological equipment has been carried out.

Based on the analysis of the results obtained, the most rational version of the design parameters of technological equipment for a wheeled skidder when working on soils with a weak bearing capacity is proposed, which allows you to minimize the dynamic loading and energy costs during the skidding process.

Key words: mathematical model, skidder, technological equipment, dynamic loading.

For citation: Isachenkov V. S., Ariko S. Ye., Simanovich V. A. On the question of choosing the parameters of the technological equipment of skidders. Proceedings of BSTU, issue 1, Forestry. Nature Management. Processing of Renewable Resources, 2021, no. 2 (246), pp. 218-223 (In Russian).

Введение. Основной процесс лесозаготовки включает в себя взаимосвязанные последовательные операции, такие как валка деревьев, обрезка сучьев, при необходимости раскряжевка на том или ином этапе, трелевка и последующая вывозка древесного сырья потребителям. 
Большинство операций на сегодняшний день выполняются комплексами машин и механизмов. Однако для значительной части лесосечного фонда, расположенного на почвогрунтах со слабой несущей способностью, остается открытым вопрос целесообразного способа трелевки. Процесс трелевки включает в себя холостой ход трелевочной машины, формирование пачки хлыстов или сортиментов, рабочий ход и разгрузку пачки на погрузочном пункте $[1,2]$. На заготовке древесного сырья в Республике Беларусь в указанных условиях работы в настоящее время используются колесные трелевочные машины (КТМ) с канатно-чокерным технологическим оборудованием, в частности ТTР-401 и ТТР-411 различных модификаций.

Для преодоления участка трелевочных или магистральных волоков со слабой несущей способностью почвогрунта при буксовании для этих машин во время рабочего хода используется прием сброса пачки с последующим ее подтаскиванием [3]. Основными путями повышения тягово-динамических качеств КТМ являются совершенствование двигателя, трансмиссии, ходовой части и обоснованный выбор типа технологического оборудования, за счет чего можно добиться перераспределения нагрузок на несущую систему в процессе движения и тем самым снизить динамическую нагруженность, а также повысить проходимость [4-7].

Для решения данной задачи предлагается изменить конструкцию технологического оборудования установкой дополнительной опорной системы с возможностью использования в качестве как навесного, так и прицепного варианта. В начальный момент буксования технологическое оборудование переводится из навесного положения в прицепное, и КТМ, не теряя темпа работы, преодолевает проблемный участок. После преодоления указанного участка технологическое оборудование переводится в навесное положение, что значительно снижает энергетические потери во время преодоления участков с удовлетворительной несущей способностью почвогрунта.

В ранее выполненных работах [8-10] были теоретически обоснованы и экспериментально подтверждены основные параметры прицепного технологического оборудования (ПТО). Однако дальнейшие исследования поставили вопрос о необходимости сравнительного анализа различных по конструктивным особенностям типов применяемого технологического оборудования, а также конструкции опорных систем ПТО.

Основным методом теоретических исследований в настоящее время является разработка математических моделей движения специаль- ных транспортных средств на основе методов системного подхода и синтеза, которые широко применяются для лесозаготовительной техники различного назначения.

В представленной работе рассматриваются динамические системы, в которых технологическое оборудование КТМ дано в прицепном варианте, а в качестве опорной системы выбрана трехосная тележка. В первом варианте выбран пачковый клещевой захват (КЗ), размещенный на специальной арке (ПА) и обозначенный как ЗПКЗ; во втором варианте манипулятор с клещевым захватом и зажимной коник (ПК), обозначенный в дальнейшем как ЗПКН.

Основная часть. Основные принципы построения расчетных схем и составления математических моделей движения КТМ, оснащенной различными по компоновочному решению типами ПТО, имеют допущения, аналогичные математическому аппарату, представленному в работе [11]. Они предполагают нахождение независимых, изменяющихся во времени координат (степеней свободы), определяющих положение всех масс, входящих в системы, при рассмотрении переходных и установившихся режимов движения.

Расчетные динамические схемы определяются следующими обобщенными координатами: вертикальным, угловым и продольным перемещением центра тяжести КТМ - $y_{1}, y_{2}, y_{3}$; вертикальным перемещением центра тяжести переднего моста КТМ - $y_{4}$; вертикальным, угловым и продольным перемещением центра тяжести ПТО (ПК и ПА) $-y_{5}, y_{6}, y_{7}$; углом поворота коленчатого вала двигателя - $y_{8}$; углами поворота колес КТМ - $y_{9}$ и $y_{10}$; вертикальными и продольными перемещениями центра тяжести КЗ и дискретных масс пачки деревьев $-y_{11}$, $y_{12}, y_{13} ;$ вертикальным перемещением центра тяжести водителя и сидения - $y_{14}$; угловым перемещением осей балансирной тележки ПТО относительно горизонтальной плоскости $-y_{15}$.

Для расчетных схем и описывающих их уравнений приняты следующие параметры: $M_{\text {д }}$ момент двигателя; $I_{\text {Д }}$ - момент инерции вращающихся масс двигателя и ведущих частей сцепления; $I_{\mathrm{K} 1}$ и $I_{\mathrm{K} 2}-$ моменты инерции элементов трансмиссии и колес КТМ, приведенные к их

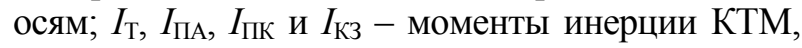
ПА, ПК и КЗ соответственно; $M_{\mathrm{T}}, m_{\mathrm{M}}, m_{\text {ПА }}$ и $m_{\text {ПК }}-$ масса КTM, подрессоренная масса переднего моста КТМ, масса ПА и ПК соответственно; $m_{\text {Кз }}, m_{2}$ и $m_{3}$ - дискретные массы клещевого захвата и пачки хлыстов; $m_{\mathrm{B}}-$ подрессоренная масса водителя и сиденья; $c_{1}$ и $k_{1}-$ коэффициент вертикальной жесткости и сопротивления переднего моста КТМ; $c_{2}, c_{3}, k_{2}$ и $k_{3}-$ коэффи- 
циенты вертикальной жесткости и сопротивления шин, установленных на колеса КТМ; $c_{41}$, $c_{42}, k_{41}$ и $k_{42}-$ коэффициенты вертикальной и горизонтальной жесткости и сопротивления сцепки КТМ с ПТО; $c_{51}, c_{52}, c_{53}, k_{51}, k_{52}$, и $k_{53}-$ коэффициенты вертикальной жесткости и сопротивления шин, установленных на колесах ПТО; $c_{61}, c_{62}, k_{61}$ и $k_{62}-$ коэффициенты горизонтальной жесткости и сопротивления шин и почвогрунта, приведенные к точкам контакта колес КТМ с трелевочным волоком; $c_{7}, c_{8}, k_{7}$ и $k_{8}-$ коэффициенты угловой жесткости и сопротивления валов привода переднего и заднего мостов КТМ; $c_{11}, k_{11}$ - коэффициенты вертикальной жесткости и сопротивления пачки хлыстов; $c_{12}, k_{12}-$ коэффициенты вертикальной жесткости и сопротивления сиденья водителя; $c_{13}, c_{14}, k_{13}$ и $k_{14}-$ коэффициенты горизонтальной и вертикальной жесткости и сопротивления в К3; $i_{1}$ и $i_{2}-$ передаточные числа приводов переднего и заднего мостов КТМ; $a, b$ и $h_{\mathrm{T}}-$ координаты центра тяжести КТМ; $l_{\mathrm{B}}$ - координата центра тяжести водителя и сиденья; $l_{\text {ПА }}$ и $h_{\text {ПА }}-$ координаты центра тяжести ПА; $l_{\Pi \kappa}$ и $h_{\Pi \kappa}-$ ко-

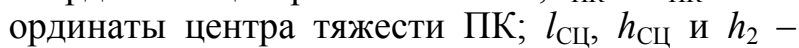
координаты точек сцепки КТМ и ПТО; $L_{\mathrm{X}}-$ длина пачки хлыстов; $l_{1}$ и $l_{2},-$ координаты центра тяжести пачки хлыстов; $h_{\text {Кз }}$ - координата КЗ относительно трелевочного волока; $l_{\text {Кз }}-$ координата центра тяжести КЗ относительно центра тяжести ПА; $l_{9}-$ расстояние от горизонтальной координаты центра балансирной тележки до центра тяжести ПТО; $l_{10}$ и $l_{11}-$ горизонтальное расстояние плеч балансирной тележки ПТО; $l_{12}$ - горизонтальное расстояние от задней оси ПТО до центра тяжести ПТО; $r_{1}$ и $r_{2}$ - радиусы качения шин колес КТМ; $r_{3}, r_{4}$ и $r_{5}-$ радиусы качения шин колес ПТО; $q_{1}$ и $q_{2}-$ текущие значения ординат микропрофиля неровностей трелевочного волока под шинами колес КТМ; $q_{3}, q_{4}$ и $q_{5}$ - текущие значения ординат микропрофиля неровностей трелевочного во-

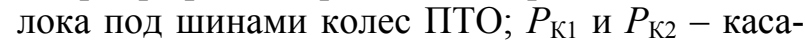
тельные силы тяги, развиваемые на колесах КТМ; $P_{F 1}$ и $P_{F 2}-$ силы сопротивления шин колес КТМ; $P_{F 3}, P_{F 4}$ и $P_{F 5}-$ силы сопротивления шин колес ПТО; $P_{V}-$ сила сопротивления волочению пачки хлыстов.

Представленные расчетные схемы динамической системы КТМ с ПТО различных компоновочных решений, разработанные с учетом ряда принятых допущений, на основе анализа ее конструкции и кинематики движения звеньев обозначаются: $a-3 П К 3$ (схема имеет пятнадцать степеней свободы); $\sigma$ - 3ПКН (схема имеет тринадцать степеней свободы) (рис. 1).

Посредством математического аппарата, на основе системы высокоуровневого программирования MATLAB 7.11.0 (R2010b), получены матрицы численных значений отклонений степеней свободы моделей, первые производные этих отклонений и соответствующие им моменты времени протекания процесса, что позволило определить все необходимые параметры оценки динамической нагруженности КТМ, оснащенной различным по типу решения ПТО.

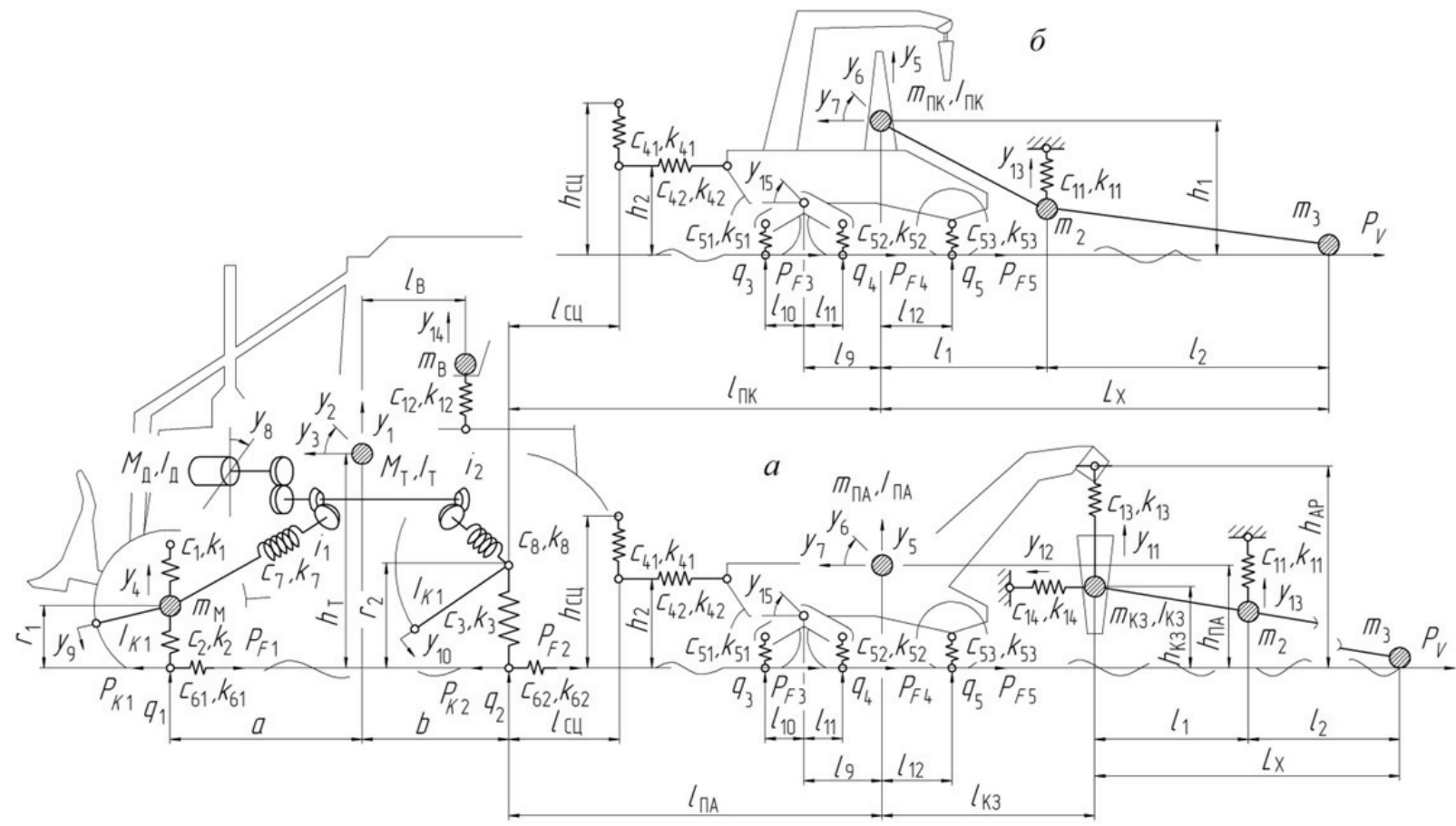

Рис. 1. Расчетные схемы динамической системы КТМ, оснащенной: $a-3 \Pi К 3 ; \sigma-3 \Pi К Н$ 
Так, изменения вертикальных ускорений по времени в центре тяжести ПТО определялись по следующим зависимостям:

а) для ЗПКЗ:

$$
\begin{aligned}
\ddot{Y}_{5}= & {\left[c_{41}\left(Y_{1}-\left(b+l_{\text {СЦ }}\right) Y_{2}-Y_{5}-\left(l_{\Pi \mathrm{A}}-l_{\text {СЦ }}\right) Y_{6}\right)+\right.} \\
+ & k_{41}\left(\dot{Y}_{1}-\left(b+l_{\text {СЦ }}\right) \dot{Y}_{2}-\dot{Y}_{5}-\left(l_{\Pi \mathrm{A}}-l_{\text {СЦ }}\right) \dot{Y}_{6}\right)- \\
& -c_{51}\left(Y_{5}+l_{10} Y_{15}+\left(l_{9}+l_{10}\right) Y_{6}-Q_{3}\right)- \\
& -k_{51}\left(\dot{Y}_{5}+l_{10} \dot{Y}_{15}+\left(l_{9}+l_{10}\right) \dot{Y}_{6}-\dot{Q}_{3}\right)- \\
& -c_{52}\left(Y_{5}-l_{11} Y_{15}+\left(l_{9}-l_{11}\right) Y_{6}-Q_{4}\right)- \\
& -k_{52}\left(\dot{Y}_{5}-l_{11} \dot{Y}_{15}+\left(l_{9}-l_{11}\right) \dot{Y}_{6}-\dot{Q}_{4}\right)- \\
- & c_{53}\left(Y_{5}-l_{12} Y_{6}-Q_{5}\right)-k_{53}\left(\dot{Y}_{5}-l_{12} \dot{Y}_{6}-\dot{Q}_{5}\right)- \\
- & \left.c_{14}\left(Y_{5}-l_{\text {К }} Y_{6}-Y_{11}\right)-k_{14}\left(\dot{Y}_{5}-l_{\text {К3 }} \dot{Y}_{6}-\dot{Y}_{11}\right)\right] / m_{\text {ПА }} .
\end{aligned}
$$

б) для ЗПКН:

$$
\begin{gathered}
\ddot{Y}_{5}=\left[c_{41}\left(Y_{1}-\left(b+l_{\text {СЦ }}\right) Y_{2}-Y_{5}-\left(l_{\Pi К}-l_{\text {СЦ }}\right) Y_{6}\right)+\right. \\
+k_{41}\left(\dot{Y}_{1}-\left(b+l_{\text {СЦ }}\right) \dot{Y}_{2}-\dot{Y}_{5}-\left(l_{\Pi \text { ПК }}-l_{\text {СЦ }}\right) \dot{Y}_{6}\right)- \\
-c_{51}\left(Y_{5}+l_{10} Y_{15}+\left(l_{9}+l_{10}\right) Y_{6}-Q_{3}\right)- \\
-k_{51}\left(\dot{Y}_{5}+l_{10} \dot{Y}_{15}+\left(l_{9}+l_{10}\right) \dot{Y}_{6}-\dot{Q}_{3}\right)- \\
-c_{52}\left(Y_{5}-l_{11} Y_{15}+\left(l_{9}-l_{11}\right) Y_{6}-Q_{4}\right)- \\
-k_{52}\left(\dot{Y}_{5}-l_{11} \dot{Y}_{15}+\left(l_{9}-l_{11}\right) \dot{Y}_{6}-\dot{Q}_{4}\right)- \\
\quad-c_{53}\left(Y_{5}-l_{12} Y_{6}-Q_{5}\right)- \\
\quad-k_{53}\left(\dot{Y}_{5}-l_{12} \dot{Y}_{6}-\dot{Q}_{5}\right)- \\
-l_{2} c_{11}\left(l_{2} Y_{5} / L_{\mathrm{X}}-Y_{13}\right) / L_{\mathrm{X}}- \\
\left.\quad-l_{2} k_{11}\left(l_{2} \dot{Y}_{5} / L_{\mathrm{X}}-\dot{Y}_{13}\right) / L_{\mathrm{X}}\right] / m_{\text {ПК }} .
\end{gathered}
$$

Изменение вертикальных ускорений центра тяжести водителя и сиденья по времени определялось по формуле

$$
\ddot{Y}_{14}=\left[-c_{12}\left(Y_{14}-Y_{1}+l_{\mathrm{B}} Y_{2}\right)-k_{12}\left(\dot{Y}_{14}-\dot{Y}_{1}+l_{\mathrm{B}} \dot{Y}_{2}\right)\right] / m_{\mathrm{B}} .
$$

В уравнениях заглавные буквы степеней свободы $\left(Y_{i}\right)$ означают полученные при моделировании матрицы результатов, их первые и, соответственно, вторые производные $\left(\dot{Y}_{i}\right.$ и $\left.\ddot{Y}_{i}\right)$, обработка которых позволила построить графики нормированных спектральных плотностей ускорений центра тяжести ПТО, центра тяжести водителя и сиденья, и их изменения в зависимости от применяемого технологического оборудования.

Динамические процессы для различных типов ПТО моделировались при равных весовых, жесткостных и других параметрах систем. В частности, рассматривался процесса трелевки КТМ пачки деревьев объемом $V_{\text {Хл }}=1,2 \mathrm{~m}^{3}$ и скорости перемещения КТМ $V=4,57$ км/ч при одинаковых характеристиках микропрофиля магистрального волока. Результаты обрабатывались методами математической статистики.

Нормированные спектральные плотности ускорения центра тяжести различных типов ПТО при движении КТМ представлены на рис. 2.

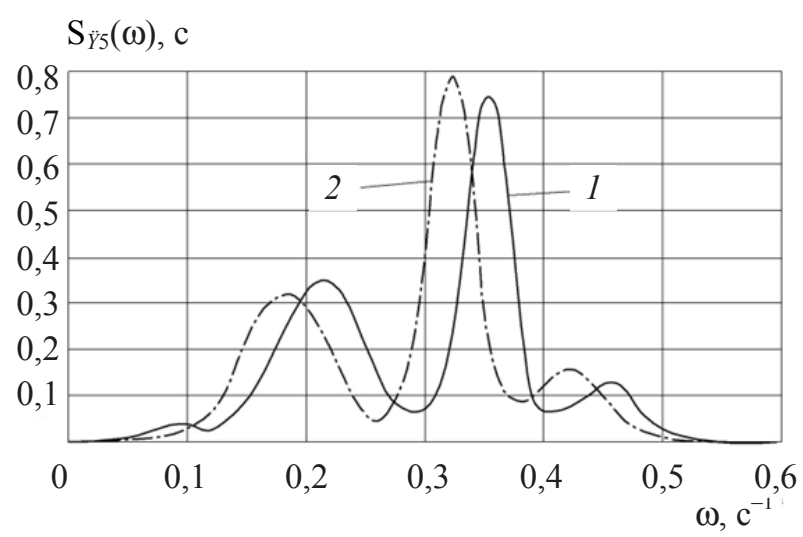

Рис. 2. Нормированные спектральные плотности вертикальных ускорений центра тяжести ПТО: $1-3 \Pi К 3 ; 2-3 \Pi К Н$

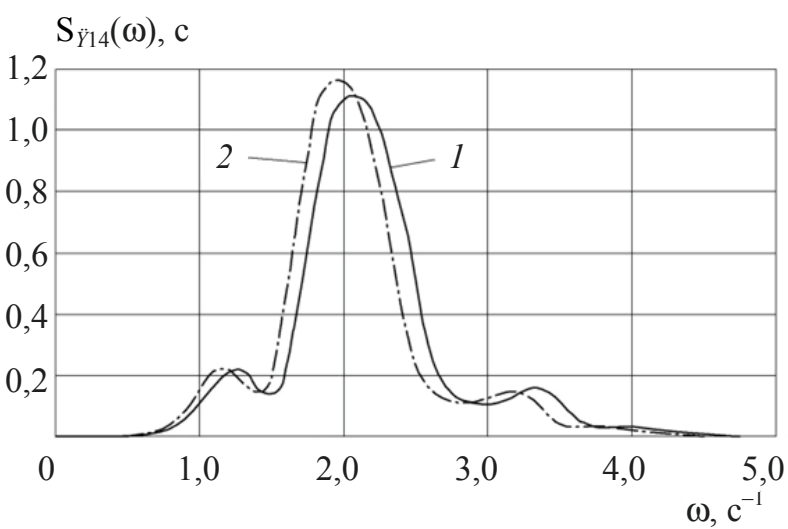

Рис. 3. Нормированные спектральные плотности вертикальных ускорений центра тяжести водителя и сидения: 1 - 3ПКЗ; 2 - 3ПКН

Для всех типов технологического оборудования максимум нормированной спектральной плотности ускорения центра тяжести ПТО проявляется дважды. Первый раз для ЗПКЗ он проявляется при частоте $0,22 \mathrm{c}^{-1}$ и достигает значе-

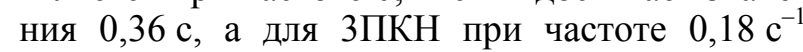
имеет значение 0,32 с. Во второй раз для 3ПКЗ при частоте $3,51 \mathrm{c}^{-1}$ он достигает $0,74 \mathrm{c}$, для ЗПКН при частоте $3,27 \mathrm{c}^{-1}-0,79 \mathrm{c}$.

Процесс снижения статистических величин ускорений затухает более интенсивно для ЗПКЗ.

Графики нормированных спектральных плотностей ускорения центра тяжести водителя и сиденья при движении КТМ показывают, что основные максимальные значения встречаются один раз и лежат в диапазоне частот от $2,0 \mathrm{c}^{-1}$ до $2,2 \mathrm{c}^{-1}$, при этом абсолютные величины максимумов зависят от применяемого типа техно- 
логического оборудования (рис. 3). Абсолютный максимум при этом уменьшается для ЗПКЗ в 1,07 раза по сравнению с ЗПКН.

Проведенными теоретическими исследованиями были определены основные весовые и геометрические размеры ПТО путем изменения входящих в динамическую систему параметров, которые влияют на процессы движения КТМ.

Сравнение полученных результатов с выполненными ранее исследованиями позволяет сделать вывод о целесообразности применения наиболее рационального прицепного технологического оборудования при работе на почвогрунтах со слабой несущей способностью [9-11].

Заключение. Проведена теоретическая оценка динамической нагруженности основных элементов конструкции колесной трелевочной машины и технологического оборудования.

На основе анализа полученных результатов предложен наиболее рациональный вариант параметров конструкции трехосного прицепного технологического оборудования для колесной трелевочной машины, которое позволяет минимизировать показатели динамической нагруженности во время трелевки на почвогрунтах со слабой несущей способностью.

Полученные параметры прицепного технологического оборудования могут быть использованы при проектировании колесных агрегатных машин для лесозаготовки на машиностроительных предприятиях.

\section{Список литературы}

1. Вырко Н. П. Сухопутный транспорт леса. Минск: БГТУ, 2003. 438 с.

2. Матвейко А. П., Клоков Д. В., Протас П. А. Технология и оборудование лесосечных и лесоскладских работ. Практикум. Минск: БГТУ, 2013. 199 с.

3. Протас П. А., Клоков Д. В. Аналитическое исследование процесса взаимодействия колесных трелевочных машин с пачкой хлыстов и волоком // Актуальные направления научных исследований XXI века: теория и практика. 2014. Т. 2, № 4-5. С. 256-260. DOI: 10.12737/7110.

4. Кононов А. М. Исследование реализации тягово-сцепных качеств и агротехнической проходимости колесных тракторов на суглинистых почвах Беларуси: автореф. дис. ... д-ра техн. наук. Горки: БСХА, 1974. $41 \mathrm{c}$.

5. Соколова В. А., Петров И. П. Исследование взаимодействия арочного колеса с опорной поверхностью // Труды НАМИ. 1962. Вып. 54. С. 64-72.

6. Хайлис Г. А. К теории качения пневматического колеса // Тракторы и сельхозмашины. 1963. № 3. С. 5-7.

7. Симанович В. А., Демидов В. А., Клоков Д. В. Колеса и шины лесных и лесотранспортных машин. Минск: БГТУ, 2005. $84 \mathrm{c.}$

8. Симанович В. А., Исаченков В. С. Оценка тягово-сцепных свойств трелевочных тракторов с усовершенствованной конструкцией несущей системы // Труды БГТУ. Сер. II, Лесная и деревообраб. пром-сть. 2009. Вып. XVII. С. 116-119.

9. Исаченков В. С., Симанович В. А. Обоснование параметров канатно-чокерного технологического оборудования // Труды БГТУ. 2012. № 2: Лесная и деревообраб. пром-сть. С. 39-42.

10. Исаченков В. С., Симанович В. А. К вопросу оценки эффективности работы колесной трелевочной машины на почвогрунтах со слабой несущей способностью // Труды БГТУ. Сер. 1, Лесное хозяйство, природопользование и переработка возобновляемых ресурсов. 2019. № 2 (222). С. 191-196.

11. Исаченков В. С., Симанович В. А. Обоснование параметров прицепного технологического оборудования колесных трелевочных машин // Труды БГТУ. 2016. № 2: Лесная и деревообраб. пром-сть. С. 23-27.

\section{References}

1. Vyrko N. P. Sukhoputnyy transport lesa [Forest land transport]. Minsk, BGTU Publ., 2003. 438 p.

2. Matveyko A. P., Klokov D. V., Protas P. A. Tekhnologiya i oborudovaniye lesosechnykh i lesoskladskikh rabot. Praktikum [Technology and equipment for logging and landing works. Practical work]. Minsk, BGTU Publ., 2013, 199 p.

3. Protas P. A., Klokov D. V. Analytical study of the interaction of wheel skidder with a bundle of stems and portage. Aktual'nyye napravleniya nauchnykh issledovaniy XXI veka: teoriya i praktika [Recent research trends of the XXI century: Theory and Practice], 2014, vol. 2, no. 4-5, pp. 256-260. DOI: $10.12737 / 7110$.

4. Kononov A. M. Issledovaniye realizatsii tyagovo-stsepnykh kachestv $i$ agrotekhnicheskoy prokhodimosti kolesnykh traktorov na suglinistykh pochvakh Belarus. Aftoref. dis. d-ra tekhn. nauk [Investigation of the realization of traction-coupling qualities and agrotechnical patency of wheeled tractors on loamy soils in Belarus. Abstract of thesis dis. DSc (Engineering)]. Gorki, BSKHA Publ., 1974. 41 p. 
5. Sokolova V. A., Petrov I. P. Study of the interaction of an arched wheel with a supporting surface. Trudy NAMI [Proceedings of NAMI], 1962, issue 54, pp. 64-72 (In Russian).

6. Haylis G. A. To the theory of the rolling of a pneumatic wheel. Traktory i sel'khozmashiny [Tractors and agricultural machinery], 1963, no. 3, pp. 5-7 (In Russian).

7. Simanovich V. A., Demidov V. A., Klokov D. V. Kolesa i shiny lesnykh i lesotransportnykh mashin [Wheels and tires forestry and transport machine]. Minsk, BGTU Publ., 2005. 84 p.

8. Simanovich V. A., Isachenkov V. S. Evaluation of traction characteristics skidders with advanced design support system. Trudy BGTU [Proceedings of BSTU], series II, Forest and Woodworking Industry, 2009, issue XVII, pp. 116-119. (In Russian).

9. Isachenkov V. S., Simanovich V. A. Rope-choker trailed implements determination of parameters. Trudy BGTU [Proceedings of BSTU], 2012, no. 2: Forest and Woodworking Industry, pp. 39-42 (In Russian).

10. Isachenkov V. S., Simanovich V. A. To question of estimation of efficiency of work of the skidder on soils with weak bearing strength Trudy BGTU [Proceedings of BSTU], issue 1, Forestry. Nature Management. Processing of Renewable Resources, 2019, no. 2 (222), pp. 191-196 (In Russian).

11. Isachenkov V. S., Simanovich V. A. Substantiation of the parameters of tow technology equipment wheeled skidders. Trudy BGTU [Proceedings of BSTU], 2016, no. 2: Forest and Woodworking Industry, pp. 23-27 (In Russian).

\section{Информация об авторах}

Исаченков Владимир Сергеевич - старший преподаватель кафедры инженерной графики. Белорусский государственный технологический университет (220006, г. Минск, ул. Свердлова, 13a, Республика Беларусь). E-mail: v.isachenkov@belstu.by.

Арико Сергей Евгеньевич - кандидат технических наук, доцент, доцент кафедры лесных машин, дорог и технологий лесопромышленного производства. Белорусский государственный технологический университет (220006, г. Минск, ул. Свердлова, 13a, Республика Беларусь). E-mail: sergeyariko@mail.ru

Симанович Василий Антонович - кандидат технических наук, доцент, доцент кафедры лесных машин, дорог и технологий лесопромышленного производства. Белорусский государственный технологический университет (220006, г. Минск, ул. Свердлова, 13a, Республика Беларусь). E-mail: lmitlz@belstu.by.

\section{Information about the authors}

Isachenkov Vladimir Sergeyevich - Senior Lecture, the Department of Engineering Graphics. Belarusian State Technological University (13a, Sverdlova str., 220006, Minsk, Republic of Belarus). E-mail: v.isachenkov@belstu.by

Ariko Sergey Yevgen'yevich - PhD (Engineering), Associate Professor, Assistant Professor, the Department of Logging Machinery, Forest Roads and Timber Production Technology. Belarusian State Technological University (13a, Sverdlova str., 220006, Minsk, Republic of Belarus). E-mail: sergeyariko@mail.ru

Simanovich Vasiliy Antonovich - PhD (Engineering), Associate Professor, Assistant Professor, the Department of Logging Machinery, Forest Roads and Timber Production Technology. Belarusian State Technological University (13a, Sverdlova str., 220006, Minsk, Republic of Belarus). E-mail: lmitlz@belstu.by 